\title{
FLOOD HAZARDS IN THE CHI RIVER BASIN, THAILAND: IMPACT MANAGEMENT OF CLIMATE CHANGE
}

\author{
ARUNYANART, N. ${ }^{*}$ - LIMSIRI, C. - UCHAIPICHAT, A. \\ Faculty of Engineering, Vongchavalitkul University \\ 84 Moo 4 Mitraparb-Nongkai Highway, Nakhonratchasima, 30000, Thailand \\ (phone: +66-4-420-3778; fax: +66-4-420-3785) \\ *Corresponding author \\ e-mail: natthakorn_arunyanart@yahoo.com; phone: +668-8553-5241; fax: +66-4-322-1741
}

(Received $18^{\text {th }}$ May 2017; accepted $2^{\text {nd }}$ Aug 2017)

\begin{abstract}
The Chi River Basin (CRB) is one of the major river basins in Thailand. Flooding often occurs in this floodplain, which has a profound effect on human life and property. Currently, climate change has a high impact on river discharges and therefore on floods. Hence, the management of flooding to minimize impacts due to climate change is essential and a priority at national and regional levels. The purpose of this study is to provide a quantitative understanding of the impacts of climate change on hydrological regimes and to provide a guideline for coping with the consequences. In this paper, General Circulation Model (GCM) outputs, the Statistical DownScaling Model (SDSM), the Soil and Water Assessment Tool (SWAT) model, the Hydrological Engineering Centre - River Analysis System (HECRAS) program, and the Geographic Information System (GIS) were used to determine areas vulnerable to flooding due to climate change. A flood hazard map was developed for the Lampao River Basin (LRB), which is a sub catchment of the CRB. According to the results, an appropriate flood management plan for the area was proposed. The plan involved structural and non-structural measures that integrated three methods of dealing with flood hazards which are modifying the hazards, moderating the impacts, and reducing the risks. Integrated flood management is a complex endeavor therefore computer-based tools that enable analysis of the whole system should be developed to implement the plan efficiently.
\end{abstract}

Keywords: climate changes impact, downscaling, flood hazard, Chi River Basin, flood management

\section{Introduction}

Climate change is one of the most critical issues in the world and in Thailand. Climate change has caused serious consequences in Thailand, such as higher surface temperatures, floods, droughts, severe storms and sea level rise (Sudtida, 2012). Over the past 30 years, there were more than 50 droughts and floods in Thailand (DEQP, 2016), and flooding is always a major problem in Thailand. Therefore, understanding the impact of climate change on flooding is vital to overcome this problem.

According to the Intergovernmental Panel on Climate Change (IPCC), General Circulation Model (GCM) can "reproduce features of the past climates and climate changes" (Randall et al., 2007). GCM are the best tools to estimate future global climate changes resulting from the continuous increase in the concentration of greenhouse gases in the atmosphere (Busuioc et al., 2001; Dibike and Coulibaly, 2005). The output of GCM can assist in understanding climate and in forecasting climate change. To simulate sub-grid scale phenomena, hydrological models are necessary, and such hydrological models require input data at a similar scale. These data are generally provided by converting the GCM outputs into a reliable regional hydrological time series at the selected catchment scale. Usually, "downscaling" techniques are used to convert GCM outputs into the local meteorological variables required for reliable hydrological modelling (Dibike and Coulibaly, 2005; Huntingford et al., 2006). 
In this study, daily precipitation series for specific area have to be obtained, therefore, the Statistical DownScaling Model (SDSM), which is a decision support tool for assessing local climate change impacts using a robust statistical downscaling technique, was selected (Kafatos, 2012). The statistically downscaled GCM outputs and the atmospheric circulation indices, as well as humidity variables derived from the CGCM3 model, were used to downscale daily precipitation series for the upper catchment of the Chi River Basin (CRB). The generated climate scenarios were then applied to drive the distributed Soil and Water Assessment Tool (SWAT) model. Changes in the modelled daily flow regime between current and future climate scenarios were compared and analysed. The impact of climate change on precipitation in the upper catchment of the Lampao River Basin (LRB), which is one of the CRB's sub-catchments, was investigated as a case study representing the Chi River Basin.

The analysed results were adopted to manage the impact of flood hazards, which concerns communities, the economy, the environment and human health. An appropriate flood management plan of the area was proposed. A flood mitigation plan was developed for critical disaster situations that affect life and property. Proper measures were presented to reduce the impact of flood hazards. The plan involves multiple projects that fall under one of two categories, i.e., hard engineering and soft engineering. The proposed plan is divided into the following:

- Early stage management (before the rainy season)

- During the occurrence of disasters (during the rainy season)

- Reconstruction plan (after disasters occur)

\section{Materials and Methods}

\section{Study Area and Data Used}

The Lampao sub-basin of the Chi River Basin for investigation in this study due to its frequency of flooding. The Chi River Basin has an area of $49.477 \mathrm{~km}^{2}$ and is divided into 20 watersheds or catchment basins, which represent $29.10 \%$ of the northeast area of Thailand. The geographical location is between latitude $15^{\circ} 30^{\prime}$ and $-17^{\circ} 30^{\prime}$ north, and longitude $101^{\circ} 30^{\prime}$ and $-104^{\circ} 30^{\prime}$ east (Kuntiyawichai, 2011), as shown in (Fig. 1).

The topography of the Chi River Basin (CRB) includes tall mountains in the east and north from the Phu Phan mountain range. The west includes the Dong Phaya Yen mountain, which is the origin of the Chi River and several other major rivers. The central area is flat to undulating, and there is a small hill in the south of the basin. The major tributaries in the Chi River Basin include Nam Prom, Nam Chen, Nam Pong, and Lampao. Reservoirs in the basin include Ubol Ratana Dam, Chulabhorn Dam, Lum Nam Pung Dam, and Lampao Dam. The average precipitation is 1,028 mm/year. Approximately 6.7 million people live in this area.

The economies of the Chi River Basin depend on farming and animal husbandry. The income per person is 80.000-100.000 Baht/year (2.280-2.860 US dollars/year) (NSO, 2016).

According to recommendations of the Intergovernmental Panel on Climate Change (IPCC), the baseline used in this study is the standard normal for the period 1961-1990, as described by the standard of the World Meteorological Organization (IPCC-TGCIA, 1999). Data from two GCM simulation models, i.e., CGCM3 and HadCM3, were used 
in this investigation. The predictor variables for CGCM3 and HadCM3, described on a grid box, are provided in Table 1.

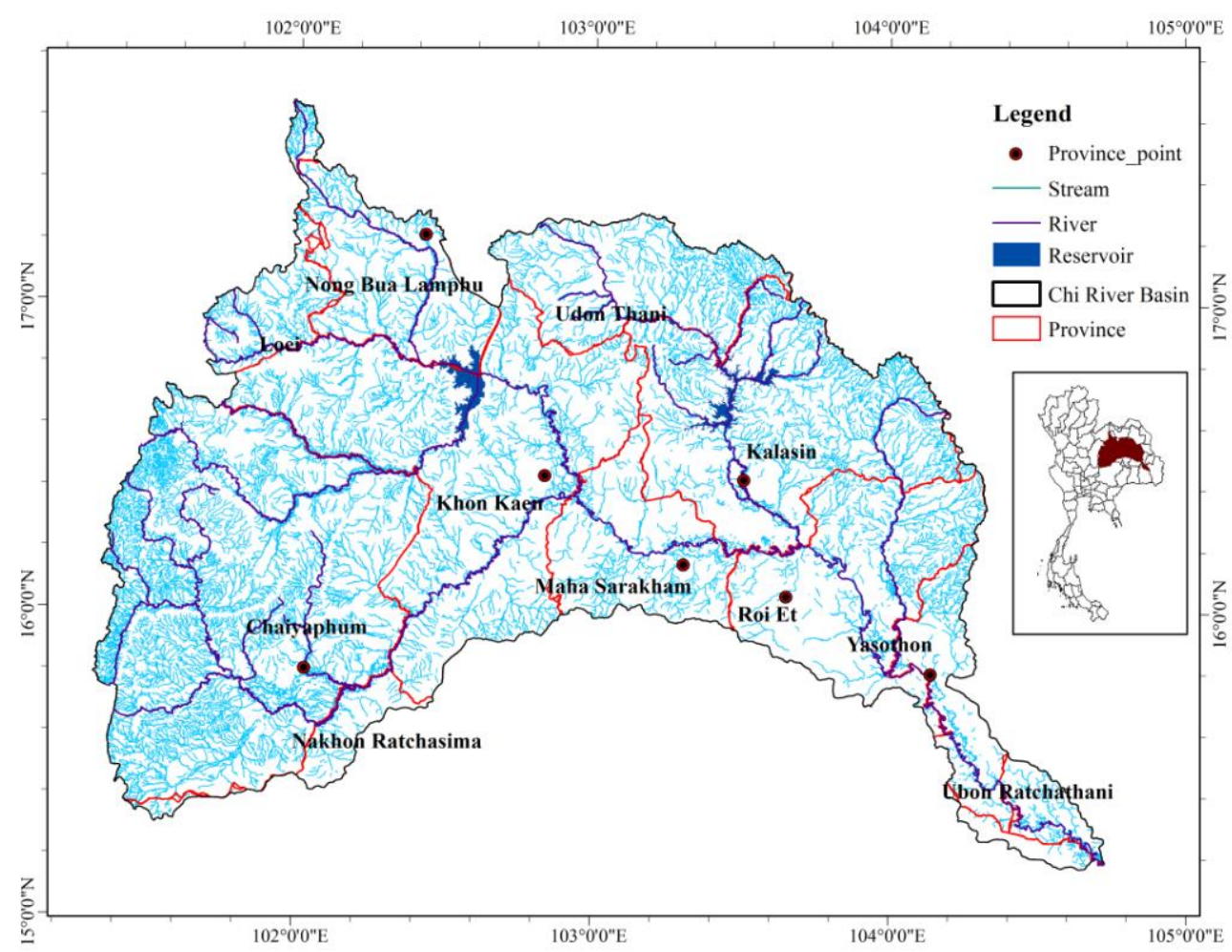

Figure 1. Chi River Basin

Table 1. Grid positions of the Chi River Basin

\begin{tabular}{c|c|c|c|c}
\hline No. & Station Name & Code & Grid Position CGCM3 & Grid Position HadCM3 \\
\hline 1 & Chaiyaphum & 403201 & $28 X \_20 Y$ & $28 X \_29 Y$ \\
2 & Khonkaen & 381201 & $28 X \_20 Y$ & $28 X \_28 Y$ \\
3 & Roiet & 405201 & $29 X \_20 Y$ & 29X_29Y \\
\hline
\end{tabular}

Three weather stations of the Thailand Meteorological Department (TMD), as detailed in Table 2, located in the study area (Fig. 2 and Fig. 3), provided daily precipitation data for CGCM3 and HadCM3. The past 50 years of data that cover the period suggested by the IPCC are available from the three stations.

Table 2. Weather station locations

\begin{tabular}{c|c|c|c|c|c}
\hline No. & Station Name & Basin & Latitude & Longitude & Level (MSL.) \\
\hline 1 & Chaiyaphum & $\mathrm{Chi}$ & $15^{\circ} 48^{\prime} 00^{\prime \prime}$ & $102^{\circ} 02^{\prime} 00^{\prime \prime}$ & 180 \\
2 & Khonkaen & $\mathrm{Chi}$ & $16^{\circ} 27^{\prime} 48^{\prime \prime}$ & $102^{\circ} 47^{\prime} 12^{\prime \prime}$ & 165 \\
3 & Roiet & $\mathrm{Chi}$ & $16^{\circ} 03^{\prime} 00^{\prime \prime}$ & $103^{\circ} 41^{\prime} 00^{\prime \prime}$ & 140 \\
\hline
\end{tabular}




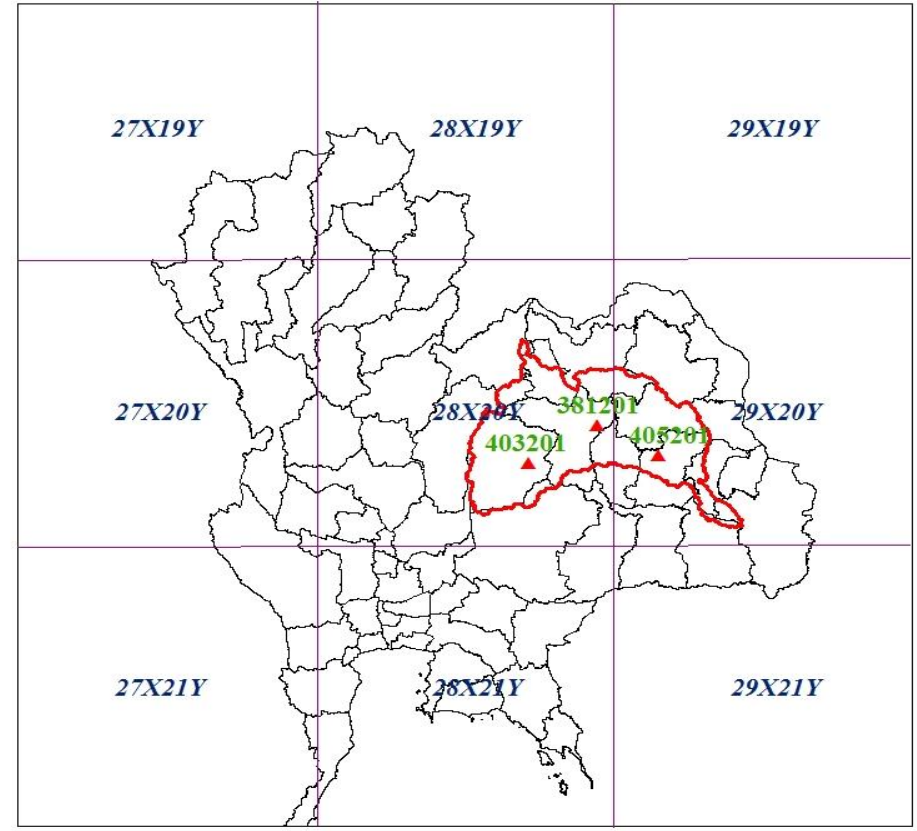

Figure 2. Location of the weather station in CGCM3

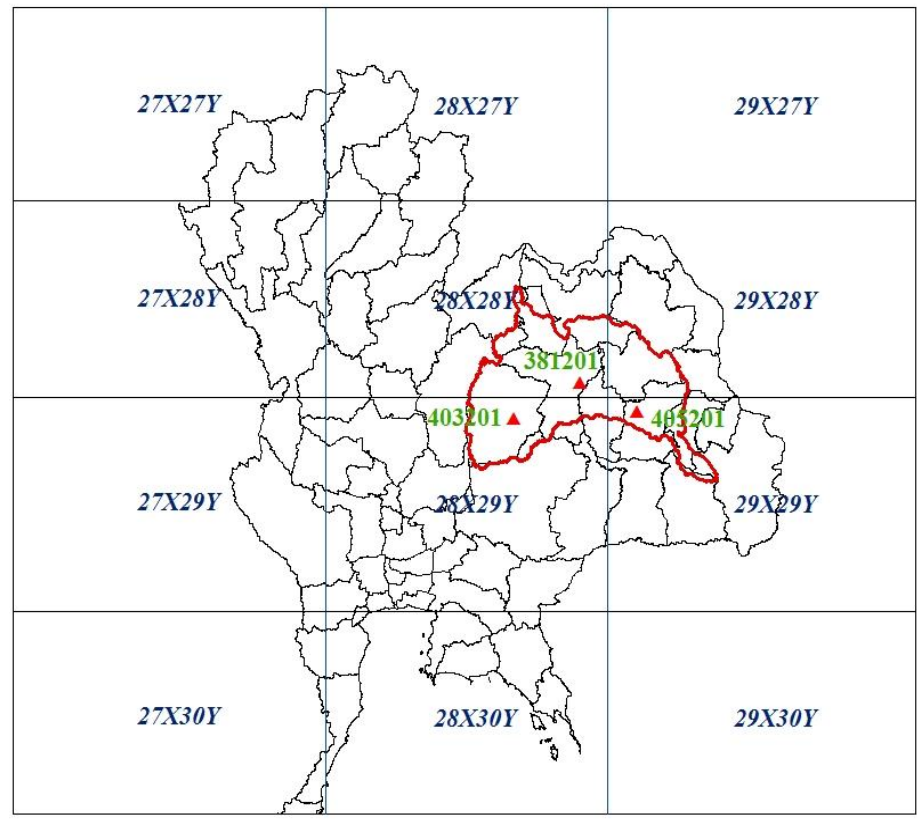

Figure 3. Location of the weather station in HadCM3

Hydrological data for the hydrological models include the following:

- Daily rainfall data from 17 TMD stations in the Lampao River Basin and nearby areas.

- Daily runoff, water level and cross section of the Lampao River from 8 stream gauge stations of the Royal Irrigation Department (RID) in the area. 
- Flood area from the Geo-Informatics and Space Technology Development Agency (Public Organization) - GISTDA.

Thus, the damage value from flooding can be evaluated in the flood area through the simulation results of the hydrological models. Damage includes loss of life and property, damage to buildings and other structures and flood health effects. These data were collected from the Department of Disaster Prevention and Mitigation.

Based on the flood risk and damage value, a flood management plan was developed to reduce the impact. This plan was compared to the existing plan of the Royal Irrigation Department that is adopted presently.

\section{Method}

The methodology of the study is shown in Fig. 4 and is described in detail as follows:

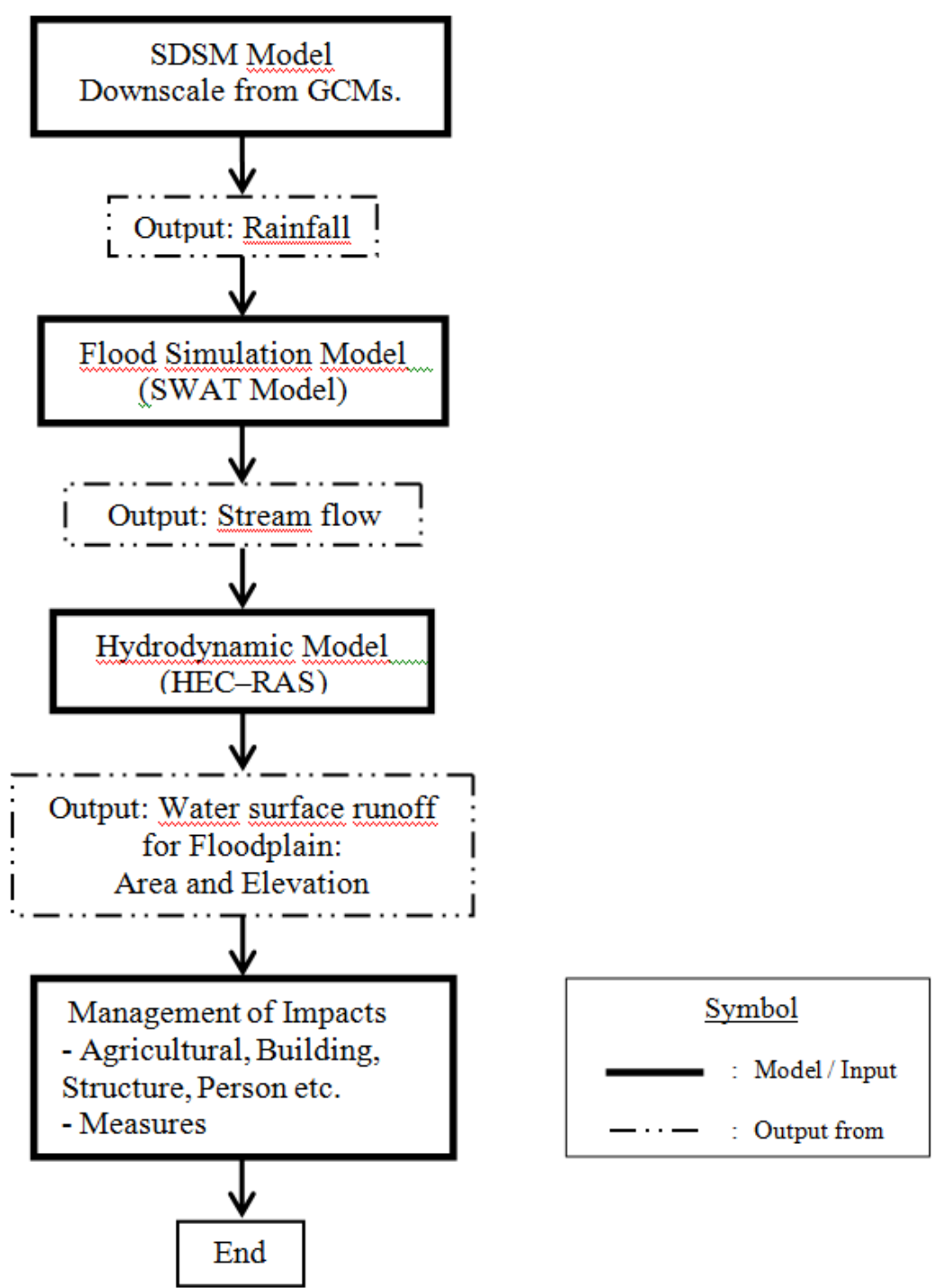

Figure 4. Study flow chart 


\section{Statistical DownScaling Model (SDSM)}

The Statistical DownScaling Model (SDSM) is a hybrid of the multiple linear regression and stochastic downscaling model developed by Rob Wilby and Christian Dawson (Harpham and Wilby, 2005; Wilby and Dawson, 2007). It is a freely available decision support tool for assessing local climate change impacts using a robust statistical downscaling technique. In the SDSM downscaling, a multiple linear regression model is developed between selected large-scale predictor variables and local-scale predictands such as temperature and precipitation. The SDSM uses a conditional process to downscale precipitation. Local precipitation amounts depend on wet/dry day occurrences.

GCMs (CGCM3 and HadCM3) approved by the Intergovernmental Panel on Climate Change (IPCC) were selected to construct climate scenarios. Data from these two international GCMs (CGCM3 and HadCM3) were obtained from the web site of the Canadian Climate Impacts and Scenarios project (http://www.cics.uvic.ca/scenarios). The source of scaling uncertainties is treated by downscaling the GCM outputs with the Statistical DownScaling Model (SDSM) (Wilby et al., 2001). This model is applied using conditional means involving stochastic weather generators.

The method used is a well-recognized statistical downscaling tool that has been made available to the broader climate change impact study community via the Canadian Climate Impact Scenarios (CCIS) project (Dibike and Coulibaly, 2005). The past 30 years of data represent the current climate (1961-1990), as recommended by the IPCC; the first 15 years are used for calibrating the regression model; and the remaining years of the data are used to validate the model.

This study applied the SDSM to predict future climate change in the Chi River Basin over 20 years, 50 years and 80 years. Changes in rainfall from the effects of climate change are obtained and used as the input in the hydrological model.

\section{Hydrological Model}

The Soil and Water Assessment Tool (SWAT) model, which has gained international acceptance as a robust interdisciplinary catchment modelling tool to quantify the impact of land management practices in large, complex catchments, was used to estimate the stream flow in LRB, because SWAT is a physically based model that is able to predict the impact of land use changes on water in a catchment and land use on a basin scale over long periods of time (Sun and Cornish, 2005). For the hydrodynamic model, the Hydrological Engineering Centre - River Analysis System (HEC-RAS) which is an accepted model to estimate surface runoff, was used (HEC, 2002).

The stream flow data measured at a stream gauging station located at Nong Mung (E.75) on the Lampao River was employed to calibrate the SWAT model. The observed data were split for calibration (2006-2009) and validation (2010-2013) purposes. Several statistical measures were used to evaluate the simulation accuracy, such as the Nash-Sutcliffe coefficient, the Root Mean Square Error, Goodness of fit and the Average Observance. Thereafter, the best calibrated model parameters were assigned to simulate stream flow with different rainfall scenarios from the SDSM to predict the tributary inflows with the probability of occurrence of flood inundation at all selected points on the Lampao River.

These stream flows were used as the input of HEC River Analysis System (HECRAS) model to determine the overflow depth of water to land subject to flooding. 


\section{Flood Hazard}

The flood depth was considered as the hazard indicator in this study. Therefore, the flood hazard categorization was adopted based on the induced flood depth. The flood hazard management model, as shown in Fig. 5, was proposed to reduce the impact of flood hazards.

Flood depth hazard maps were constructed based on the specific maximum flood depth with the probability of non-exceedance at $20 \%, 50 \%$, and $80 \%$. These maps are very useful for flood control and flood hazard management.

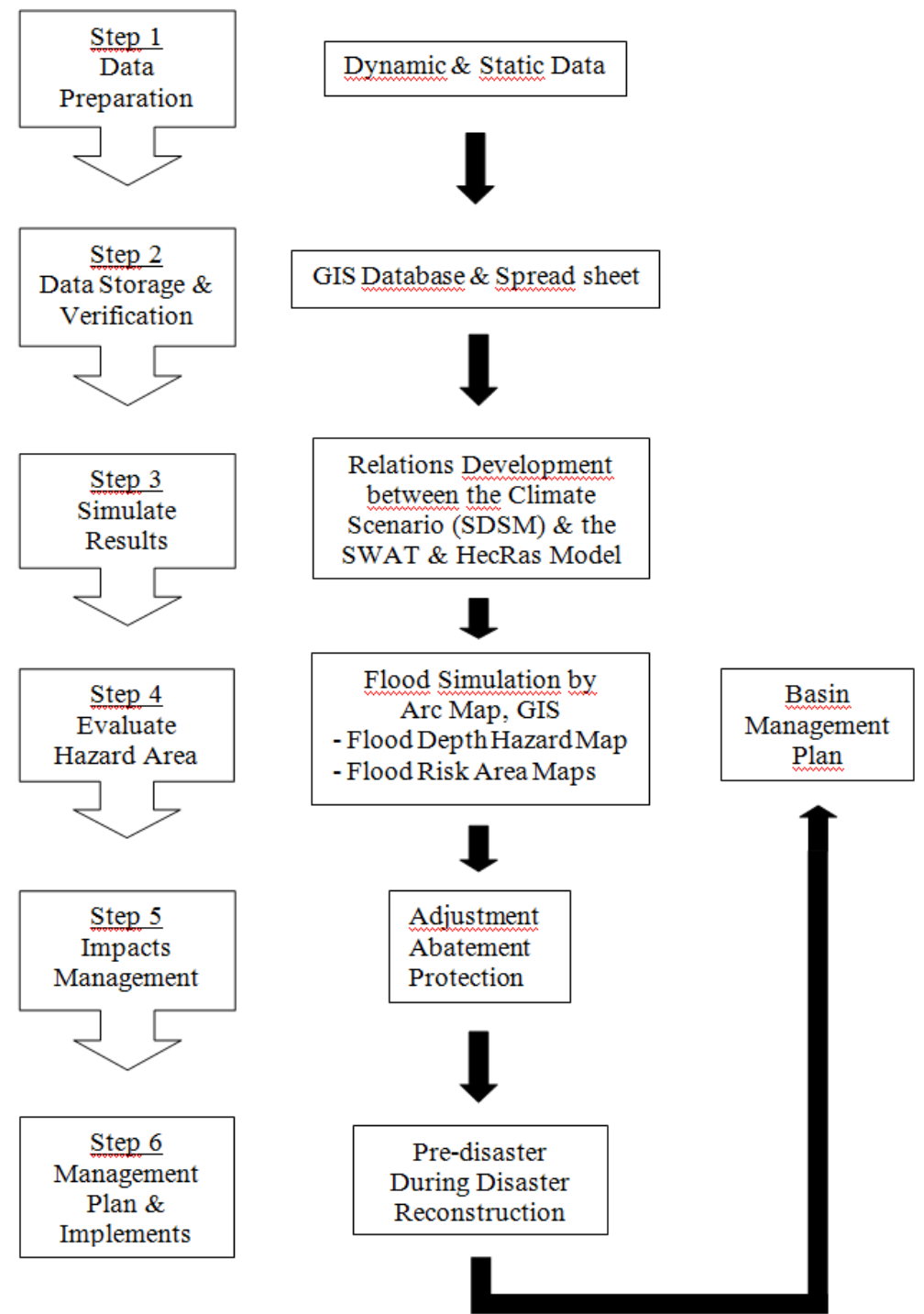

Figure 5. Flood management model

\section{Results and Discussion}

\section{Choice of Predictor Variables}

The National Centre for Environmental Prediction (NCEP) provides re-analysis data and GCM data used by SDSM. The data are available from 1961 to -1990. 
Comparison of the predictor variables of the two GCMs, i.e., CGCM3 and HadCM3, can be selected by the entry screening method to obtain the least error results and the least used predictor variables. Large-scale predictor variables representing the current climate conditions, derived from the NCEP reanalysis data sets, were used to investigate the percentage of variance in each predictand-predictor pair. The most relevant predictor variables from the downscaling experiments from three weather stations in the area, i.e., Chaiyaphum (CPM), Khonkaen (KKN) and Roiet (RET), were determined and are shown in Table 3.

Table 3. The relevant NCEP predictors from downscaling

\begin{tabular}{c|c|c|c|c|c|c}
\hline \multirow{2}{*}{$\begin{array}{c}\text { Predictors } \\
\text { No. }\end{array}$} & \multicolumn{3}{|c|}{ NCEP(CGCM3) } & \multicolumn{3}{c}{ NCEP (HadCM3) } \\
\cline { 2 - 7 } & \multicolumn{3}{|c|}{ Stations } & \multicolumn{3}{c}{ Stations } \\
\cline { 2 - 6 } & CPM & KKN & RET & CPM & KKN & RET \\
\hline ncepshumgl.dat & $\checkmark$ & $\checkmark$ & $\checkmark$ & & & \\
ncepp_vgl.dat & $\checkmark$ & & & & & \\
nceps500gl.dat & $\checkmark$ & & $\checkmark$ & & & \\
ncepp8zhgl.dat & & & $\checkmark$ & & & \\
nceps850gl.dat & & & $\checkmark$ & & & \\
ncepr500as.dat & & & & $\checkmark$ & $\checkmark$ & $\checkmark$ \\
ncepp5_zas.dat & & & & $\checkmark$ & & $\checkmark$ \\
ncepshumas.dat & & & & $\checkmark$ & & $\checkmark$ \\
ncepp_vas.dat & & & & & & $\checkmark$ \\
\hline
\end{tabular}

\section{SDSM Model Calibration and Validation}

The coefficient of the multiple linear regression equation parameters that relate the large-scale atmospheric variables derived from NCEP and the local-scale variables was obtained by model calibration. The temporal resolution of the downscaling model for precipitation downscaling was specified as daily for Chaiyaphum, Khonkaen and Roiet.

From the 30 years of data, representing the current climate conditions, the first 15 years of data (1961-1975) were considered during calibration of the regression model while the remaining 15 years (1976-1990) were used to validate the model. Table 4 shows the statistical results of CGCM3 and HadCM3 from three stations. From the NCEP selected variables, the results show that the CPM station (403201) prefers CGCM3 to HadCM3. For the KKN station (381201), HadCM3 provides better results than CGCM3. In addition, for the RET station (405201), CGCM3 is better than HadCM3. Therefore, CGCM3 was chosen for rainfall forecasting in the Chi River Basin $(\mathrm{CRB})$.

\section{Rainfall Forecast}

The prediction of future rainfall was conducted for three periods, i.e., 2011-2040, 2041-2070 and 2071-2100. The prediction results were compared with rainfall observations in the years 1961-2010. The statistical evaluation results for the validation of SDSM are also shown in Table 4. The results are quite accurate and acceptable. 
Table 5 and Fig. 6 show the computed results in the prediction of rainfall using CGCM3 and the baseline observation.

Table 4. Statistical evaluation results for the validation of SDSM

\begin{tabular}{|c|c|c|c|c|c|c|c|}
\hline & & & & & & & \\
\hline & Statistic & 40320 & CPM) & 38120 & KKN) & 405201 & (RET) \\
\hline & & CG & Had & CG & Had & CG & Had \\
\hline & $\mathrm{R}^{2}$ & 0.991 & 0.992 & 0.991 & 0.992 & 0.960 & 0.943 \\
\hline Е & Avg. Obs. & 3.234 & 3.234 & 3.234 & 3.234 & 3.945 & 3.945 \\
\hline$\sum^{\infty}$ & RMSE & 0.805 & 0.137 & 0.805 & 0.137 & 0.570 & 0.055 \\
\hline & Nash. Coef. & 0.912 & 0.997 & 0.912 & 0.997 & 0.973 & 1.000 \\
\hline$\Xi$ & $\mathrm{R}^{2}$ & 0.714 & 0.528 & 0.714 & 0.528 & 0.701 & 0.661 \\
\hline छ & Avg. Obs. & 84.550 & 78.717 & 84.550 & 78.717 & 89.850 & 89.850 \\
\hline 式 & RMSE & 16.253 & 13.942 & 16.253 & 13.942 & 29.637 & 20.480 \\
\hline$\Sigma$ & Nash. Coef. & 0.767 & 0.824 & 0.767 & 0.824 & 0.752 & 0.882 \\
\hline & $\mathrm{R}^{2}$ & 0.881 & 0.901 & 0.881 & 0.901 & 0.891 & 0.890 \\
\hline Е & Avg. Obs. & 94.110 & 98.277 & 94.110 & 98.277 & 134.316 & 134.316 \\
\hline $\bar{z}$ & RMSE & 33.230 & 18.977 & 33.230 & 18.977 & 61.809 & 32.044 \\
\hline$y$ & Nash. Coef. & 0.830 & 0.941 & 0.830 & 0.941 & 0.786 & 0.943 \\
\hline 0 & $\mathrm{R}^{2}$ & 0.984 & 0.970 & 0.984 & 0.970 & 0.969 & 0.953 \\
\hline $\bar{\Xi}$ & Avg. Obs. & 17.180 & 17.013 & 17.180 & 17.013 & 20.297 & 20.297 \\
\hline$\underset{J}{0}$ & RMSE & 4.206 & 1.921 & 4.206 & 1.921 & 5.157 & 2.492 \\
\hline & Nash. Coef. & 0.918 & 0.983 & 0.918 & 0.983 & 0.915 & 0.980 \\
\hline & $\mathrm{R}^{2}$ & 0.977 & 0.995 & 0.977 & 0.995 & 0.960 & 0.942 \\
\hline$\Xi$ & Avg. Obs. & 117.894 & 99.311 & 117.894 & 99.311 & 120.420 & 120.420 \\
\hline$\tilde{\omega}$ & RMSE & 16.384 & 2.376 & 16.384 & 2.376 & 17.820 & 1.854 \\
\hline & Nash. Coef. & 0.974 & 0.999 & 0.974 & 0.999 & 0.999 & 0.999 \\
\hline
\end{tabular}

Table 5. Precipitation forecast from the CGCM3 model

\begin{tabular}{c|c|c|c|c|c}
\hline \multirow{2}{*}{$\begin{array}{c}\text { Station } \\
\text { Code }\end{array}$} & Model & \multicolumn{4}{|c}{ Average Annual Rainfall (mm.) } \\
\cline { 3 - 6 } & $\begin{array}{c}\text { Grid } \\
\text { CGCM3 }\end{array}$ & $\begin{array}{c}\mathbf{1 9 6 1 - 2 0 1 0} \\
\text { Baseline }\end{array}$ & $\mathbf{2 0 1 1 - 2 0 4 0}$ & $\mathbf{2 0 4 1 - 2 0 7 0}$ & $\mathbf{2 0 7 1 - 2 1 0 0}$ \\
& $28 \mathrm{X} 20 \mathrm{Y}$ & $1,227.72$ & $1,421.25$ & $1,453.22$ & $1,497.70$ \\
\hline $381201(\mathrm{KKN})$ & $29 \mathrm{X} 20 \mathrm{Y}$ & $1,375.30$ & $2,316.81$ & $2,757.65$ & $3,579.56$ \\
\hline
\end{tabular}

In Table 5, the forecast results indicate that from now to the year 2100, rainfall in the Chi River Basin will increase due to climate change. Compared with the baseline, the rainfall at the KKN station (381201) during 2011-2040, 2041-2070 and 2071-2100 will increase by $15.76 \%, 18.37 \%$ and $21.99 \%$, respectively. In addition, at the RET station (405201), a $68.46 \%, 100.51 \%$ and $160.27 \%$ increase in rainfall will occur. This indicates that the potential of flooding should increase in this area the future. 


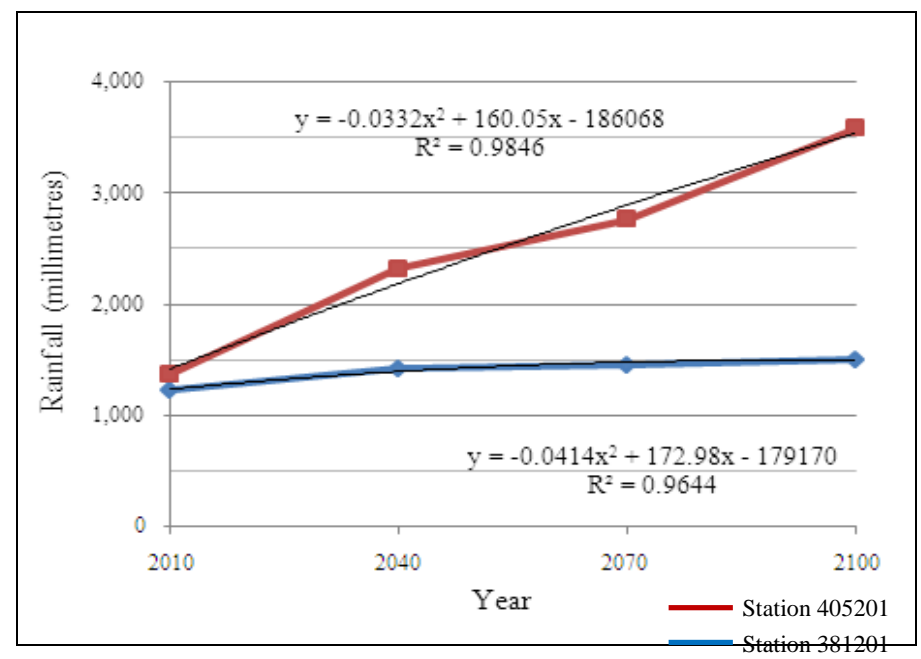

Figure 6. Precipitation forecast in Chi River Basin

The average annual rainfall between 2010 and 2100 can be predicted from the equations given in Fig. 6. The equation representing the KKN station (381201) is y = $-0.0414 \mathrm{x}^{2}+172.98 \mathrm{x}-179,170$ with $\mathrm{R}^{2}=0.9644$, where $\mathrm{y}$ is the average annual rainfall (millimetres) and $\mathrm{x}$ is the year. In addition, the average annual rainfall at the RET station $(405201)$ can be obtained by the equation $\mathrm{y}=-0.0332 \times 2+160.05 \mathrm{x}-186,068$ with $\mathrm{R}^{2}=0.9846$.

\section{SWAT Model Calibration and Validation}

The historical discharge records from the E.75 stream gauge station on the Lampao River at Kalasin province from 2006 to 2013 were split into two sets of data. The first is 2006-2009 for calibration, and the second is 2010-2013 for validation of the SWAT model. Model calibration was conducted by comparing the SWAT simulated results with the observed discharge monthly. The simulated results of the monthly stream flow and the observed stream flow are compared for calibration in Fig. 7 and for validation in Fig. 8.

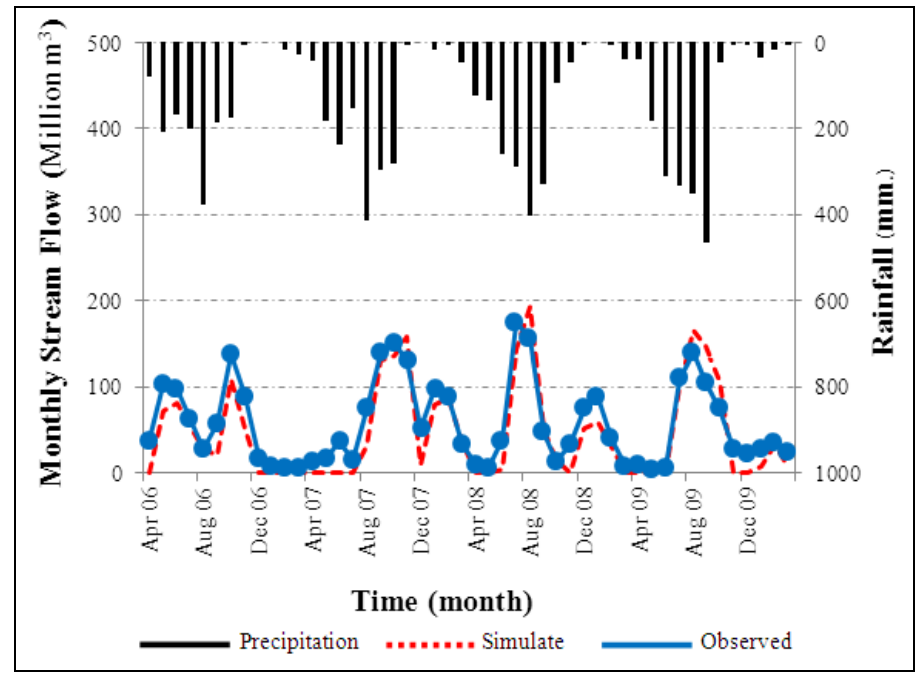

Figure 7. Calibration results of the SWAT model (2006-2009) 


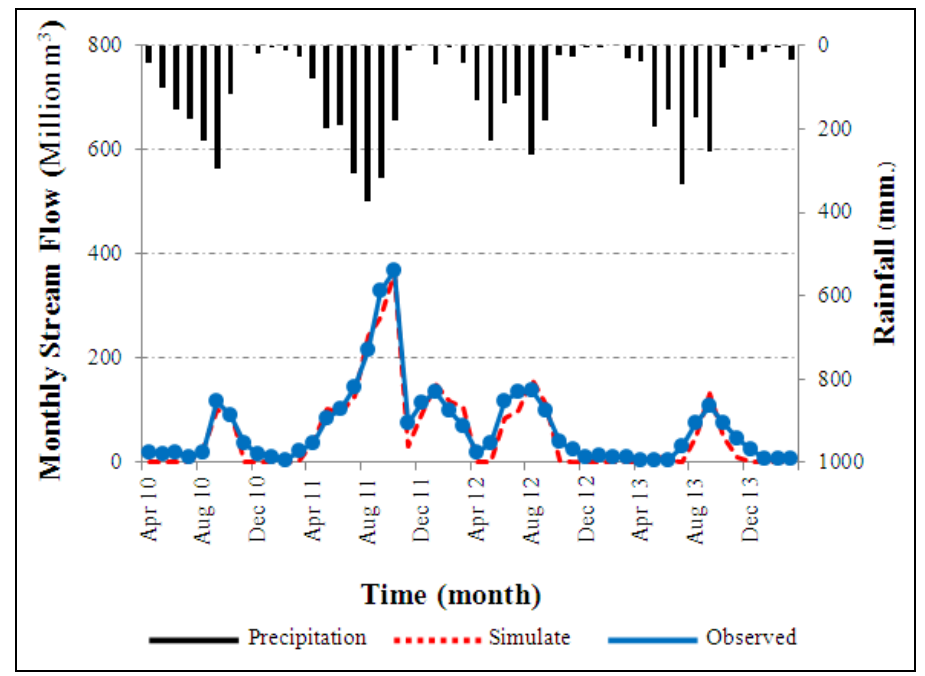

Figure 8. Validation results of the SWAT model (2010-2013)

From these figures, the simulated and observed monthly stream flow agree quite well; therefore, this SWAT model can be used to determine hydrological processes in this river basin. The evaluation of the statistical measurement error in the calibration and validation of the SWAT model is given in Table 6.

Table 6. Statistical evaluation of the measurement error in the calibration and validation of the SWAT model

\begin{tabular}{c|c|c}
\hline \multirow{2}{*}{$\begin{array}{c}\text { Evaluation } \\
\text { Statistics }\end{array}$} & \multicolumn{2}{|c}{ Station E.75 } \\
\cline { 2 - 3 } $\mathrm{R}^{2}$ & 0.873 & Validation \\
\hline Avg.Obs. & 57.681 & 0.940 \\
RMSE & 23.247 & 67.514 \\
Nash. Coef. & 0.769 & 22.633 \\
\end{tabular}

To obtain the stream flow, the downscale predicted precipitation results were input to the SWAT model to simulate the stream flow in different scenarios. The simulation results are shown in Table 7 and Fig. 9. The maximum daily stream flows during 20112040, 2041-2070, and 2071-2100 are 220.79, 239.44, and $258.09 \mathrm{~m}^{3} / \mathrm{s}$, respectively. Compared with the baseline, the maximum daily stream flow will decrease by $30.18 \%$ in the next ninety years. From the simulation model, the average annual stream flow, average annual water volume, and the highest annual stream flow show an increasing trend, but the maximum daily stream flow from the model is lower than the maximum daily stream flow recorded due to a large flood in this area in 2011. 
Table 7. Simulation results of the SWAT model for the Lampao River at station E.75

\begin{tabular}{c|c|c|c|c|c|c}
\hline \multicolumn{2}{c|}{ Period } & $\begin{array}{c}\text { Average } \\
\text { Annual } \\
\text { Stream Flow }\end{array}$ & Increase & $\begin{array}{c}\text { Average } \\
\text { Annual Water } \\
\text { Volume }\end{array}$ & Increase & $\begin{array}{c}\text { Max. Daily } \\
\text { Stream Flow }\end{array}$ \\
\hline & & $\mathbf{( \mathbf { m } ^ { 3 } / \mathbf { s } )}$ & $\mathbf{( \% )}$ & $\mathbf{( m e g a c e n t i m e t r e s )}$ & $\mathbf{( \% )}$ & $\mathbf{( \mathbf { m } ^ { 3 } / \mathbf { s } )}$ \\
\hline Baseline & $2006-2011$ & 28.39 & - & 898.36 & - & 369.67 \\
2020 & $2011-2040$ & 82.47 & $190.50 \%$ & $2,606.92$ & $190.19 \%$ & 220.79 \\
2050 & $2041-2070$ & 89.50 & $215.27 \%$ & $2,829.33$ & $214.94 \%$ & 239.44 \\
2080 & $2071-2100$ & 96.58 & $240.21 \%$ & $3,053.02$ & $239.84 \%$ & 258.09 \\
\hline
\end{tabular}

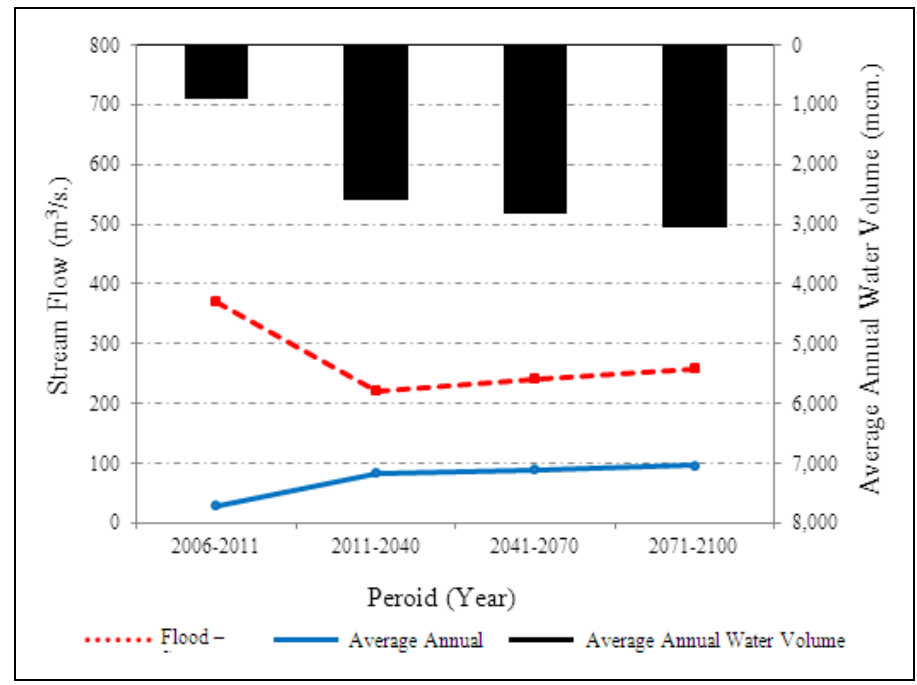

Figure 9. Summary of simulation results of SWAT model

\section{Flood Area}

Data of the maximum daily stream flow and flooding in the area were extracted from the Geo-Informatics and Space Technology Development Agency (Public Organization) - GISTDA (GISTDA, 2012). The accumulated annual stream flow and flood area from 2006 to 2011 are given in Table 8.

Table 8. Flood area of the Lampao River Basin

\begin{tabular}{c|c|c}
\hline Year & Flood Area $\left(\mathbf{k m}^{\mathbf{2}}\right)$ & Max Daily Stream Flow $\left(\mathbf{m}^{\mathbf{3}} / \mathbf{s}\right)$ \\
\hline 2006 & 41.29 & 71.50 \\
2007 & 154.67 & 350.19 \\
2008 & 34.71 & 89.88 \\
2009 & 15.20 & 133.36 \\
2010 & 102.94 & 157.40 \\
2011 & 192.88 & 369.67 \\
\hline Average & 90.28 & 193.06 \\
\hline
\end{tabular}

To determine the flood area for the next ninety years, the stream flow simulation results were input to HEC-RAS to compute the resulting water surface elevation. These 
elevations were mapped in ArcGIS to form a flood inundation map. As a result of the flood area shown in Table 9, the maximum flood area due to climate change in the next ninety years is less than the maximum flood area in the past.

Table 9. Flood area caused by climate change

\begin{tabular}{c|c|c|c}
\hline \multicolumn{2}{c|}{ Period } & Maximum daily & Flood Area \\
\hline \multicolumn{2}{c|}{} & Stream Flow $\left(\mathbf{m}^{\mathbf{3}} / \mathbf{s}\right)$ & $\left(\mathbf{k m}^{\mathbf{2}}\right)$ \\
\hline Baseline & $2006-2011$ & 369.67 & 192.88 \\
2020 & $2011-2040$ & 220.79 & 115.20 \\
2050 & $2041-2070$ & 239.44 & 124.93 \\
2080 & $2071-2100$ & 258.09 & 134.66 \\
\hline
\end{tabular}

The results show an increase in the maximum daily stream flow from 2012 to 2100 as well as the flood area. When compared to the baseline flood area, the future maximum flood area is lower due to one extraordinary flood in 2011. If the average daily stream flow and flood area are considered, the future runoff and flood area is larger than the baseline, and an increasing trend for the future is noticed.

The flood depth is considered to be the most important indicator of the intensity of the flood hazard. Therefore, the inundation area is classified into three classes according flood depth, as shown in Table 10. The flood height represents the severity, in which a low level causes inconvenience, a medium level causes the inundation of low lying areas and requires the evacuation of some areas, and a high level is widespread flooding causing extensive damage to people. A flood hazard map was constructed according to the inundation area, water height classification, and risk.

Table 10. Flood stage classification

\begin{tabular}{c|c}
\hline Level & Water Height $\mathbf{( c m})$. \\
\hline High & $>40$ \\
Medium & $20-40$ \\
Low & $<20$ \\
\hline
\end{tabular}

The river overflow data consists of the maximum water height and flood duration collected in the field, as shown in Table 11. The runoff-water height relationship can be established from these data.

Table 11. Duration of flood and maximum annual water height of river overflow

\begin{tabular}{c|c|c}
\hline Year & Duration of flood (days) & Maximum Annual Water Height (cm) \\
\hline 2006 & - & 10.00 \\
2007 & 20 & 50.00 \\
2008 & - & 15.00 \\
2009 & - & 20.00 \\
2010 & - & 25.00 \\
2011 & 18 & 55.00 \\
\hline Average & 6.33 & 29.17 \\
\hline
\end{tabular}




\section{Flood Management}

Currently, there are many agencies in Thailand involved in water management. This leads to inconsistent and non-integrated water management plans and actions. At least twelve government agencies are responsible for flood control, and there is a little cooperation among these agencies. Most of the existing flood plans are emergency plans developed independently by some of these government agencies. Thus, an integrated flood plan consisting of preparation, response, recovery, and mitigation of flood risk needs to be developed. Therefore, a flood management plan to reduce the impact on communities, the economy, the environment and health for this area was constructed as follows. It is important that lessons from the past, knowledge and technology, effective communication and applications are considered. The plan contains three phases:

- Early stage management (before the rainy season)

- During the occurrence of disasters (during the rainy season)

- Reconstruction plan (after disasters occur)

Three factors, i.e., human behaviour and decisions, probabilities of flood event and damage, and government responsibility are integrated in the plan. Traditionally, flood prevention has relied on civil engineering works. In recent years, soft measures, such as flood warning systems, flood-plain zoning, insurance, etc., have become more recognized. The management approach varies in the different phases. In this study, the optimization of the two means has been considered. The objective is to protect people and property from the damaging impacts of floods resulting climate change.

To cope with the problem, the relationship between the stream flow and flood area was determined. The major flood in 2011, which is incident in this area, which has the highest of daily stream flow $369.67 \mathrm{~m}^{3} / \mathrm{s}$ and the highest of flood area $192.88 \mathrm{~km}^{2}$, was set as the calibrated data. The result of the input data to the HEC-RAS model is shown in Fig. 10. Table 12 shows the simulation results from the HEC-RAS model, from which the relationship between the flood area and stream flow in the Lampao River Basin can be constructed.

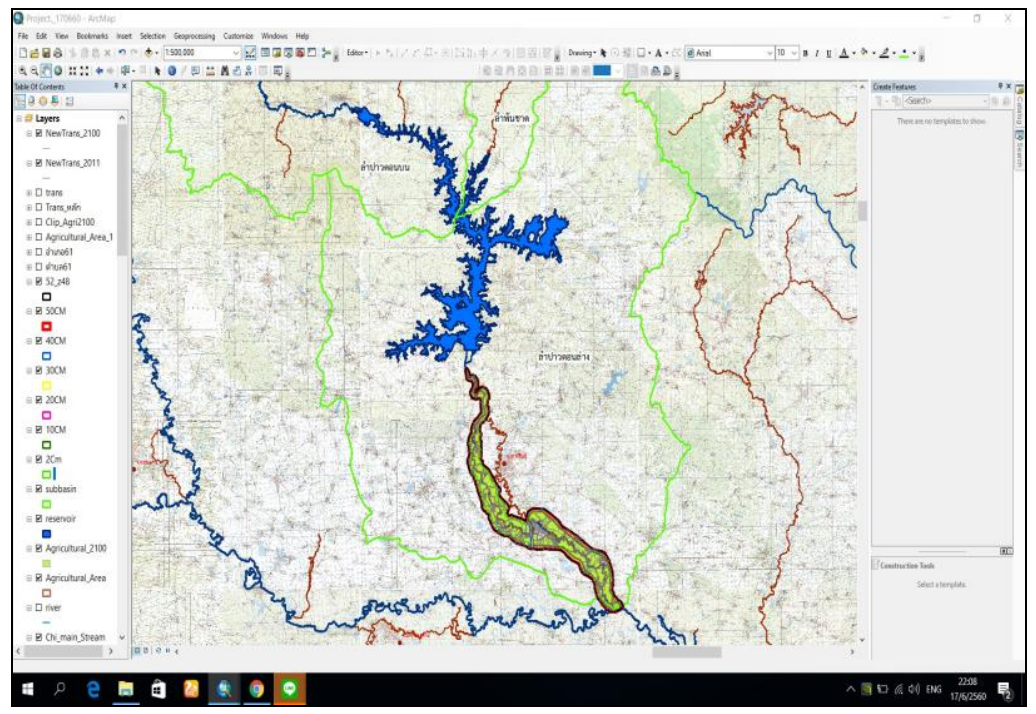

Figure 10. The flood area from the HEC-RAS model superimposed on a topographic map $1: 50,000$ 
Table 12. Flood area and stream flow in the Lampao River Basin

\begin{tabular}{c|c|c|c}
\hline Flood Area $\left(\mathbf{k m}^{\mathbf{2}}\right)$ & Stream Flow $\left(\mathbf{m}^{\mathbf{3}} / \mathbf{s}\right)$ & Flood Area $\left(\mathbf{k m}^{2}\right)$ & Stream Flow $\left(\mathbf{m}^{\mathbf{3}} \mathbf{s}\right)$ \\
\hline 0.00 & 209.53 & 114.24 & 343.15 \\
1.70 & 250.94 & 115.93 & 344.12 \\
9.39 & 274.72 & 121.86 & 347.14 \\
10.56 & 276.63 & 141.29 & 351.99 \\
24.56 & 288.57 & 162.82 & 359.50 \\
48.86 & 305.18 & 168.39 & 361.01 \\
80.34 & 328.55 & 180.37 & 365.50 \\
80.41 & 328.69 & 191.41 & 368.29 \\
102.70 & 339.15 & 192.88 & 369.67 \\
\hline
\end{tabular}

From Fig. 11, the relationship between the stream flow and flood area in the Lampao River Basin can be represented as

$$
Y=0.0118 X^{2}-5.6557 X+673.84
$$

where $\mathrm{X}$ is the stream flow $\left(\mathrm{m}^{3} / \mathrm{s}\right)$ and $\mathrm{Y}$ is the flood area $\left(\mathrm{km}^{2}\right)$, with $\mathrm{R}^{2}=0.9959$.

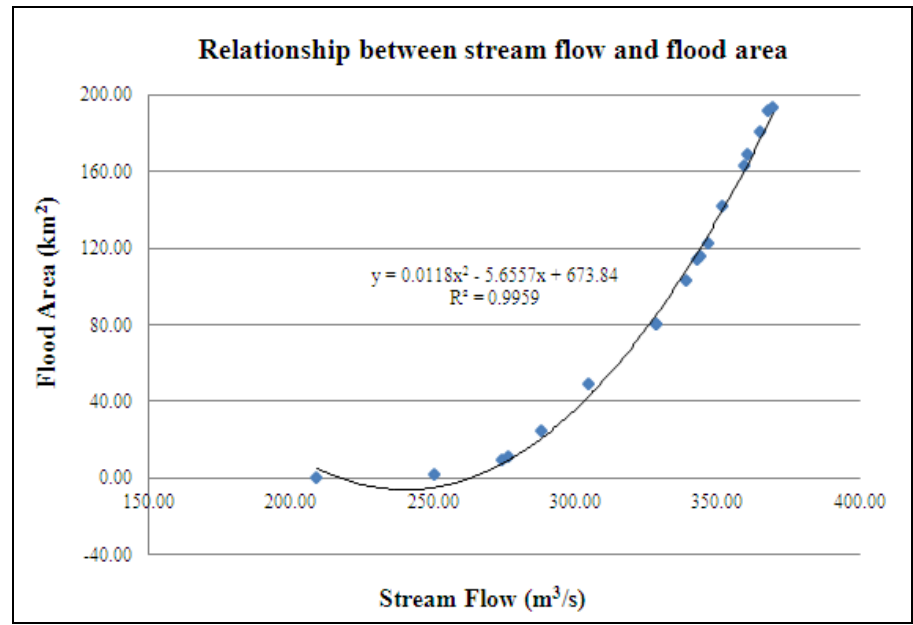

Figure 11. Relationship between the stream flow and flood area

The statistical data of flooding in the past are in agreement with this equation. Due to field operation, the stream flow can be obtained from the water height, which is more practical to measure. Therefore, the relationship between the stream flow and flood level was constructed, as shown in Fig. 12, as follows:

$$
Y=0.0015 X^{2}-0.4916 X+33.821
$$

where $\mathrm{X}$ is the stream flow $\left(\mathrm{m}^{3} / \mathrm{s}\right)$ and $\mathrm{Y}$ is the flood level $(\mathrm{cm})$, with $\mathrm{R}^{2}=0.9752$. 


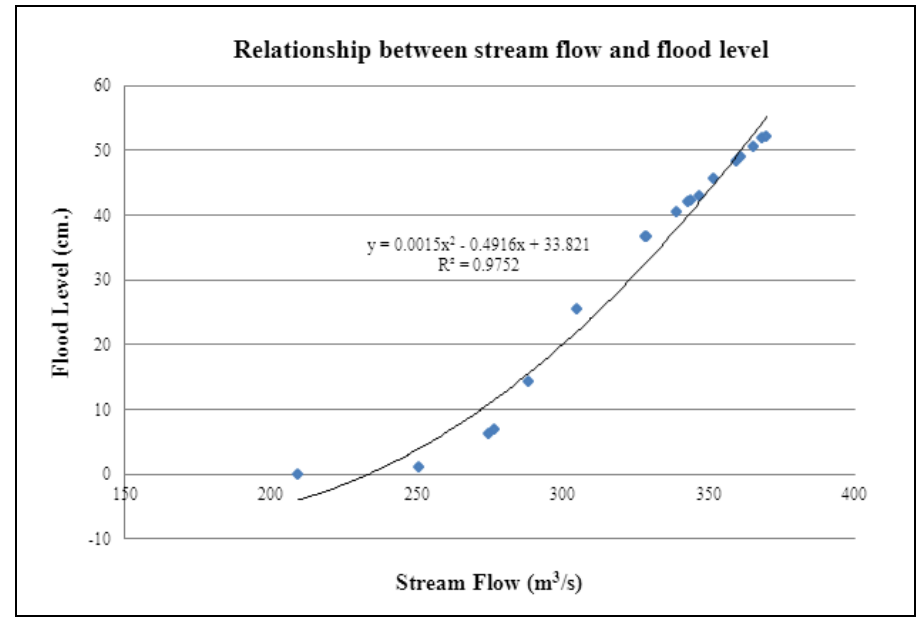

Figure 12. Relationship between the stream flow and flood level

The probability of flooding can be determined from the flood level, as shown in Fig. 13, and correlations of the flood probability to the flood level, stream flow and flood area are shown in Table 13. Through comparison with the flood stage classification in Table 8, a flood risk area map can be obtained.

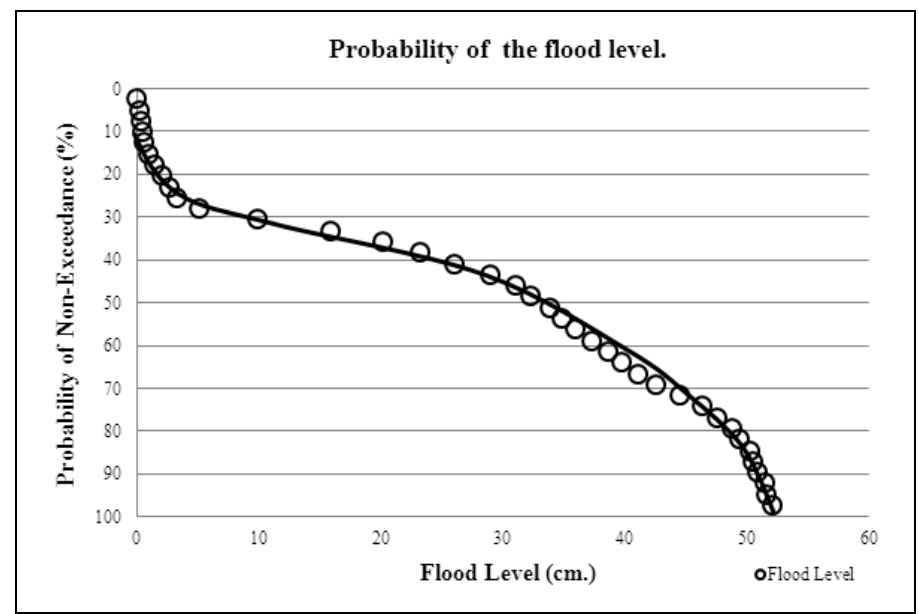

Figure 13. Probability of the flood level

Table 13. Probability of non-exceedance of the flood level

\begin{tabular}{c|c|c|c}
\hline $\begin{array}{c}\text { Probability of } \\
\text { Non-exceedance }(\boldsymbol{\%})\end{array}$ & $\begin{array}{c}\text { Flood level } \\
(\mathbf{H})(\mathbf{c m})\end{array}$ & $\begin{array}{c}\text { Stream Flow } \\
(\mathbf{Q})\left(\mathbf{m}^{\mathbf{3}} \mathbf{s}\right)\end{array}$ & $\begin{array}{c}\text { Flood Area } \\
(\mathbf{A})\left(\mathbf{k m}^{\mathbf{2}}\right)\end{array}$ \\
\hline 0.00 & 0.00 & 209.53 & 0.00 \\
10.00 & 3.23 & 261.04 & 4.96 \\
30.00 & 9.68 & 281.13 & 15.84 \\
50.00 & 27.78 & 310.05 & 55.42 \\
70.00 & 43.33 & 347.75 & 124.29 \\
90.00 & 50.36 & 364.93 & 178.85 \\
\hline
\end{tabular}




\section{Impact Management of the Flood Hazard}

Floods impact both individuals and communities, and have social, economic, and environmental consequences. In Thailand, the governmental mechanisms are available for managing flood hazards. Because of the inefficiency of integration and collaboration, flood hazards still are an unsolved problem. Therefore, it is urgent to develop a method to effectively manage flood hazards. This study proposes the flood management plan to cope with the problem. The plan is aimed at assisting the stakeholder to undertake their flood management responsibilities and ensure that suitable measures are be implemented. The plan comprises three phases, i.e., early stage management, during the disaster and reconstruction. Four general strategies, i.e., modify the loss, modify vulnerability, modify the event and modify the cause, were applied in this plan. Activities according to this plan are presented as follows:

\section{Early Stage Management}

It is essential that communities recognize flooding as part of their environment. They must be aware of the flood potential. In this stage, four activities should be applied.

- Mapping of potential flood zones

Flood hazard mapping and risk assessment were conducted to identify priority areas and high-risk zones. The inundation areas, corresponding to the flood depth, should be determined.

\section{- Asset management}

Flood mitigation assets are maintained in a fit-for-purpose state to ensure they work as designed during a flood. All flood defence structures, including waterways, should have ongoing inspection and maintenance programs. The asset should be managed in accordance with the asset management guidelines and asset management plans. Asset conditions should be assessed and reported annually.

- Planning controls

Local agencies should to consider planning permits for land use and development projects with regard to area conditions to ensure that flood control systems continue to function properly. Providing necessary information to stakeholders on the importance of appropriate design and mitigation of flooding is a good practice. Any new developments should be adequately studied and designed to protect the community and environment from flooding. The assessment of planning permit applications should focus on flooding impacts and risks. The continued assessment of flood risks at the planning permit application stage has resulted in more appropriate development in known flood risk areas. Integration and communication among responsible agencies are essential.

- Community education and awareness

Steps to create awareness of preparedness measures within the community should be taken. Public participation and public perception are important components of success. Flood preparedness education programs should be implemented. These programs will ensure that stakeholders are aware of flood impacts and appropriate flood response actions. Appropriate behaviour during the occurrence of flood events is an important element in the minimization of losses. Notification of the amendment, along with flood maps and up-to-date data, makes flooding information readily accessible to the community. 


\section{During the Occurrence of Disasters}

Two activities should be implemented as follows:

- Flood warning system

Flood warning systems and services aim to reduce losses and impacts caused by flooding and are important flood mitigation measures. Two important outcomes from flood warning systems are informing those at risk of flooding and appropriate actions being taken by those at risk. Currently there is no warning system in the area of this study; alerts of the water height according to flood hazard maps by radio, telephone, short message service (SMS) and internet, including social media, are proposed. The water height should be reported every hour. The warning message should be sent when the stream flow reaches 200 $\mathrm{m}^{3} / \mathrm{s}$, and reports should continue at 15 -minute intervals. Instruction should also be included in all messages.

- Flood emergency planning

Flood emergency planning is crucial to ensure an effective, proactive emergency response to flooding. All stakeholders must be recognized and well informed of this plan, which should be applied within the legislated framework. The plan should facilitate a consistent and coordinated approach to flood response within the risk area in the lead up to, during and immediately after a flood event. All arrangements should detail in the plan. This plan should be put into action by the community and government agencies. Communication and consultation are essential for success.

\section{Reconstruction}

This stage involves decisions regarding the return to normal activities after a period of flooding. After a flood occurs, impacts should be evaluated, and mitigation plans should be implemented. Post-disaster recovery measures should be taken as follows:

- Rebuilding

Immediately after the flood, houses, public services, infrastructures, e.g., roads, electricity, and the water supply, are rebuilt or repaired.

- Insurance and tax adjustments

Assistance and relief in the form of low-cost and subsidized insurance and taxes should be provided, along with low-cost loans. This would relieve the short-term stresses of the community.

- Income generating activities

Supporting income generating activities of members of the community is a high priority. The community should return to a normal activity and income by any means as fast as possible.

- Flood plan evaluation

To reduce the risk of floods in the future, lessons from past floods should be considered. Collecting important data, such as stream flow, flood areas, flood duration, emergency plan implementation, and mental health surveys is essential. A revise flood plan should be generated for the next early stage management step.

In this area, the impacts and risks to people and property were studied. To mitigate climate change in the future, applying the proposed flood management plan will produce less impact as seen in Table 14. 
Table 14. Risk to people and property in the Lampao River Basin during a flood event

\begin{tabular}{c|c|c|c|c}
\hline Impacted & Unit & Current & Future & Decrease(\%) \\
\hline Number of People & People & 7,079 & 6,358 & 10.19 \\
Number of Properties & Family & 1,863 & 1,287 & 30.92 \\
Agriculture & Square Kilometre & 163.69 & 112.96 & 30.99 \\
Infrastructure & Square Kilometre & 1.80 & 1.23 & 31.67 \\
\hline
\end{tabular}

\section{Catastrophe Stress of Flooding in the Lampao River Basin}

A survey of catastrophe stress of flooding was conducted in the Lampao River Basin sometime after when a major flood in 2011. The standard inquires of catastrophe stress, as determined by Department of Mental Health, Ministry of Public Health (ST5), were conducted. Effects on mental health from the stress of flooding were assessed in a community survey of 900 people, and the results are given in Table 15.

Table 15. Catastrophe stress of flooding in the Lampao River Basin

\begin{tabular}{c|c|c}
\hline Stress level & $\begin{array}{c}\text { Number of People } \\
\text { (people) }\end{array}$ & $\begin{array}{c}\text { Percentage } \\
(\boldsymbol{\%})\end{array}$ \\
\hline Minor & 127 & 14.11 \\
Gentle & 325 & 36.11 \\
Considerable & 313 & 34.78 \\
Severe & 135 & 15.00 \\
\hline Sum & 900 & 100.00 \\
\hline
\end{tabular}

Flood victims face several problems simultaneously, such as inconvenienced living, loss of property, loss of income, etc. These issues can lead to stress, anxiety, and depression. Mental illness treatment should be provided for an indefinite time until the community mental health recovers. Community mental health is a good indicator for evaluating the success of a flood management plan and should be considered in the revised plan.

\section{Conclusion}

Climate change poses significant risk to the Chi River Basin. This study responds to the needs of decision makers to plan for flooding caused by climate change. A quantitative study of the impacts of climate change based on hydrological regimes and of managing the impacts is presented. A sub-catchment, i.e., the Lampao River Basin, was used to yield detailed results for the entire basin. An increase in precipitation was observed, with the consequence of increasing the risk of rain-induced flooding. Regional climate scenarios, particularly for precipitation, were derived from SDSM to downscale climatic data for stream flow modeling of the Lampao River Basin. The results show that the SDSM provides adequate downscaled precipitation data using CGCM3 predictors. Stream flows are obtained from imputing different scenarios of precipitation data to the SWAT and HEC-RAS models and using the results to develop 
flood hazard maps. A flood management plan was presented as a useful tool so that all sectors can be aware of vulnerabilities and more efficiently cope with flooding.

While the plan was developed with simulated flood-related legislation and supporting policies and strategies, it recognizes that no single approach comprises an effective response to flood management issues. It also recognizes that it is not possible and to eliminate areas subject to flooding within the region, as a residual risk will remain.

Development of computer-based tools that enable analysis of the whole system, evaluation of the consequences of strategic intervention and coordination of intervention activities as a flood decision support system could be a beneficial research.

Acknowledgements. The authors thank members of the Faculty of Engineering, Vongchavalitkul University, for valuable consulting and guidance for this study. The authors also thank the government agencies of the Royal Irrigation Department (RID) and the Meteorological Department for useful information.

\section{REFERENCES}

[1] Busuioc, A., Chen, D., Hellstrom, C. (2001): Performance of statistical downscaling models in GCM validation and regional climate change estimates: application for Swedish precipitation. - International Journal of Climatology 21 (5): 557-578.

[2] DEQP. (2016): Department of Environmental Quality Promotion. Technical report. Community-based management on climate change problem in Thailand. - Bangkok.

[3] Dibike, Y. B., Coulibaly, P. (2005): Hydrologic impact of climate change in the Saguenay watershed: comparison of downscaling methods and hydrologic models. Journal of Hydrology (Amsterdam) 307 (1/4): 145-163.

[4] Harpham, C., Wilby, R. L. (2005): Multi-site downscaling of heavy daily precipitation occurrence and amounts. - Journal of hydrology 312 (1-4): 235-255.

[5] HEC. (2002): River Analysis System: Hydraulic Reference Manual. - US Army Corps of Engineers, Hydrologic Engineering Center, Davis, CA.

[6] Huntingford, G., Gash, J., Glacomello, A. M. (2006): Climate change and hydrology: next steps for climate models. - Hydrology Processes 20: 2085-87.

[7] IPCC-TGCIA. (1999): Guideline on the Use of Scenario Data for Climate Impact and Adaptation Assessment. Version 1. - In: Carter, T. R., Hulme, M., Lal, M. (eds.) Intergovernmental Panel on Climate Change, Task Group on Scenarios for Climate Impact Assessmsnt, 69.

[8] Kafato, M. C. (2012): Climate Change and Regional Impacts on Agriculture and Ecosystems in Semi-arid Regions. - Center of Excellence in Earth Systems Modeling and Observations. Chapman University, Orange, CA, USA.

[9] Kuntiyawichai, K., Schultz, B., Uhlenbrook, S., Suryadi, F. X., Corzo, G. A. (2011a): Comprehensive flood mitigation and management in the Chi River Basin, Thailand. Lowland Technology International 13 (1): 10-18.

[10] NSO. (2016): National Statistical Office of Thailand. National income report. - Bangkok.

[11] Randall, D. A., Wood, R. A., Bony, S., Colman, R., Fichefet, T., Fyfe, J., Kattsov, V., Pitman, A., Shukla, J., Srinivasan, J., Stouffer, R.J., Sumi, A., Taylor, K. E. (2007): Climate Models and Their Evaluation. - In: Solomon, S., Qin, D., Manning, M., Chen, Z., Marquis, M., Averyt, K. B., Tignor, M., Miller, H. L. (eds.). Climate Change (2007): The Physical Science Basis. Contribution of Working Group I to the Fourth Assessment Report of the Intergovernmental Panel on Climate Change. Cambridge University Press, Cambridge, United Kingdom and New York, NY, USA. 
[12] Sudtida, P. T. (2012): Climate Change Impacts on Water Resources: Key challenges to Thailand CC adaptation. - 7th THAIRID NATIONAL SYMPOSIUM, Bangkok, Thailand.

[13] Sun, H., Conish, P. S. (2005): Estimating shallow groundwater recharge in the headwaters of the Liverpool Plains using SWAT. - Hydology Processes 19: 795-807.

[14] Wilby, R. L., Dawson, C. W., Barrow, E. M. (2001): Enhanced resolution modeling study on anthropogenic climate change: changes in extremes of the hydrological cycle. - Int. J. Climatol. 22: 755-777.

[15] Wilby, R. L., Dawson, C. W. (2007): SDSM 4.2 - A decision support tool for the assessment of regional climate change impacts, User Manual. 